\title{
Spatial analysis of phylogenetic community structure: New version of a classical method
}

\author{
C. Ricotta ${ }^{1,6}$, E. Ari², G. Bonanomi ${ }^{3}$, F. Giannino 3 , D. Heathfield ${ }^{4}$, S. Mazzoleni ${ }^{3}$ \\ and J. Podani ${ }^{5}$
}

'Department of Environmental Biology, University of Rome 'La Sapienza', Rome, Italy

2Department of Genetics, Eötvös University, Budapest, Hungary

'Department of Agicultural Sciences, University of Naples 'Federico II', Portici, Italy

${ }^{4}$ World in a Box, Karkkila, Finland

${ }_{5}^{5}$ Department of Plant Systematics, Ecology and Theoretical Biology, Eötvös University, Budapest, Hungary and

Ecology Research Group of the Hungarian Academy of Sciences, Budapest, Hungary

${ }^{6}$ Corresponding author: Department of Environmental Biology, University of Rome 'La Sapienza',

Piazzale Aldo Moro 5,00185 Rome, Italy.E-mail: carlo.ricotta@uniroma1.it

Keywords: Community assembly; Individual-centered analysis; Marked point patterns; Phylogenetic distances; Randomization methods

\begin{abstract}
The increasing availability of phylogenetic information facilitates the use of evolutionary methods in community ecology to reveal the importance of evolution in the species assembly process. However, while several methods have been applied to a wide range of communities across different spatial scales with the purpose of detecting non-random phylogenetic patterns, the spatial aspects of phylogenetic community structure have received far less attention. Accordingly, the question for this study is: can point pattern analysis be used for revealing the phylogenetic structure of multi-species assemblages? We introduce a new individual-centered procedure for analyzing the scale-dependent phylogenetic structure of multi-species point patterns based on digitized field data. The method uses nested circular plots with increasing radii drawn around each individual plant and calculates the mean phylogenetic distance between the focal individual and all individuals located in the circular ring delimited by two successive radii. This scale-dependent value is then averaged over all individuals of the same species and the observed mean is compared to a null expectation with permutation procedures. The method detects particular radius values at which the point pattern of a single species exhibits maximum deviation from the expectation towards either phylogenetic aggregation or segregation. Its performance is illustrated using data from a grassland community in Hungary and simulated point patterns. The proposed method can be extended to virtually any distance function for species pairs, such as functional distances.
\end{abstract}

Nomenclature: Simon (1992).

Abbreviation: MPD - Mean Phylogenetic Distance.

\section{Introduction}

Community assembly is usually assumed to represent two types of opposing processes: habitat filtering, which selects for species with similar environmental requirements, thus constraining permitted traits and trait combinations within certain limits, and mechanisms of limiting similarity (including competition, density-dependent interactions, etc.), which tend to reduce co-occurrence of ecologically similar species (Thompson et al. 2010). An indirect way for testing the degree to which variability in species function regulates species coexistence is through the analysis of phylogenetic community structure. Given the strong link between phylogeny and variation in functional traits (Losos 2008), functionally related species are likely to share a common phylogenetic history. Therefore, for traits that are phylogenetically conserved the phylogenetic dispersion of a species assemblage should reflect to some extent its functional dispersion (Webb et al. 2002, Cavender-Bares et al. 2009).

In addition to the fact that measuring relevant functional characters is sometimes more difficult than obtaining phylogenetic data and trees, phylogeny may be preferred against trait based methods when focus is on identifying overall non-random assembly mechanisms. It may be difficult to know exactly which traits are the most important in driving community assembly and which ones should be taken into consideration. Indeed, some of the traits used may convey redundant information or may be less important for overall community assembly in a specific environment. Furthermore, since species functional performance is expected to be driven by complex interactions among traits that are not independent from each other (e.g., Milla et al. 2009), phylogeny represents the mean effect of all assembly forces (Cadotte et al. 2010). Indeed, Kraft and Ackerly (2010) showed that phylogenetic 
community tests captured much of the same filtering patterns detected by trait-based methods.

Besides its relevance as a potential surrogate for ecological or functional similarity, the phylogenetic relatedness of species is per se a relevant indicator of community assembly. For instance, theories of species coexistence emphasize spatial separation as an essential factor for maintaining the diversity of many communities (Chave et al. 2002). In this view, the spatial aggregation of conspecifics induced by local dispersal needs to be disrupted to some extent by mechanisms increasing within-species segregation, like distance- or density-dependent mortality (Chesson 2000). Such inverse relationship between local conspecific density and individual performance has been related to the activity of host-specific insects or fungi (Janzen 1970, Connell 1971), the build-up of negative plant-soil feedback due to the accumulation of species-specific soil-borne pathogens (Packer and Clay 2000, van der Putten et al. 1993), the changing composition of soil microbial communities (Bever 1994, Klironomos 2002), or the release of autotoxic compounds from decaying litter (Singh et al. 1999, Mazzoleni et al. 2015a, 2015b). All these mechanisms, which are linked to the physical and chemical properties of plants rather than to their functional characters, will locally increase species diversity by reducing the chance of conspecific juveniles to colonize sites close to adult individuals. In most cases, such processes are not mutually exclusive because, for example, plant-soil negative feedback induced by phytotoxic compounds released during litter decomposition could be enhanced by the activity of soil-borne pathogens (Bonanomi et al. 2010).

In addition, recent studies have emphasized the role of phylogenetic relatedness among species in driving densitydependent community processes (Webb et al. 2006, Gonzalez et al. 2010, Metz et al. 2010, Ness et al. 2011, Paine et al. 2012). This phylogenetic generalization of density-dependent community processes is supported by observations that herbivores such as insects may target a range of closely related species (Coley and Barone 1996, Novotny et al. 2010) or that the success of pathogen transmission between tree species is increased if the species are phylogenetically related (Gilbert and Webb 2007).

Information about the impact of phylogenetic structure on species coexistence has been usually obtained by measuring correlation or association between phylogenetic distance and species co-occurrence in selected sampling units (Webb et al. 2002). The observed measure is then assessed against an appropriate null model to determine whether the species that cooccur in a sample plot have stronger or weaker than expected phylogenetic relationship (Hardy 2008). While a number of distinct measures and computer programs have been broadly applied to different communities and trophic levels as well as across different spatial and phylogenetic scales to detect non-random phylogenetic patterns (reviewed in Vamosi et al. 2009), only a few papers have explored the spatial aspects of phylogenetic community structure (e.g., Seidler and Plotkin 2006, Ferrier et al. 2007, Devictor et al. 2010, Morlon et al. 2010). The aim of this paper is thus to introduce a new proce- dure for analyzing the scale-dependent phylogenetic structure of multi-species assemblages based on digitized field data.

\section{A phylogenetic extension of individual-centered analysis}

Species interactions result in spatial patterns, which can be described as marked point patterns (Diggle 2003, Illian et al. 2008, Law et al. 2009). In addition to the spatial coordinates of individual plants represented by the points, marked point patterns provide information on the properties of each object, like species identity, size, etc. (Grabarnik et al. 2011). The method proposed in this paper is thus a generalization of individual-centered analysis (Podani and Czárán 1997), which is in turn the multispecies extension of Ripley's (1981) second-order analysis of point patterns. Given a portion of the Earth's surface in which the positions of all individual plants are recorded in a two-dimensional coordinate system, Ripley's approach basically consists in calculating the average number of conspecifics found within a certain distance from each individual of a given species, divided by the number of conspecifics per unit area. This value is then compared with the expected value that results if the same number of individuals is randomly distributed across the study area. Likewise, in our proposal the sampling method involves taking a circular sample plot of a given radius $\mathrm{R}$ around each plant and counting the number of neighboring individuals within the circle. The mean phylogenetic distance (MPD) between the center (or focal) individual and all neighbors (including conspecifics of the focal individual) is then calculated within each circle and averaged over all individuals of the same species. Next, deviation of the observed value from null expectation of complete spatial randomness in species distribution (implying that there are no biotic interactions amongst neighboring individuals) is tested for significance based on randomization methods.

To examine dependence of MPD on distances from the focal individual, the same procedure is repeated for a range of increasing values of R and MPD is calculated for all individuals located in the circular ring delimited by two successive radii. The application of this multi-scale method reveals particular radius values at which the point pattern exhibits maximum deviation from the expectation towards either species aggregation or segregation. One advantage of the proposed individual-centered sampling strategy is that each species can be analyzed separately, providing information for the assessment of its own role on community assembly (Podani and Czárán 1997).

\section{Case study}

\section{Field data}

To evaluate the performance of the proposed method, we used an historical data set sampled in 1996 in a sand-steppe community near Bugac (Kiskunság National Park, Hungary). The exact position and identity of all individual plants and 

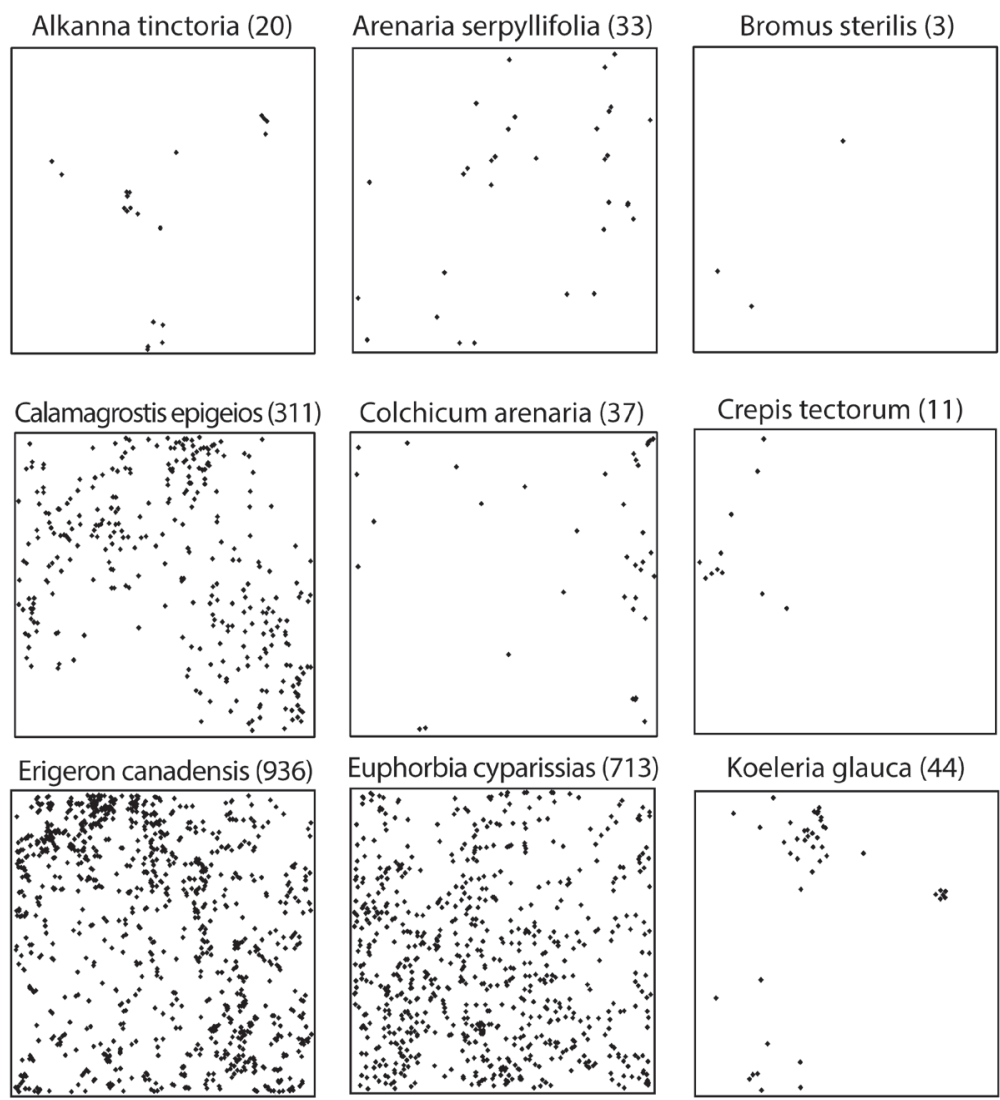

Euphorbia cyparissias (713)

Koeleria glauca (44)
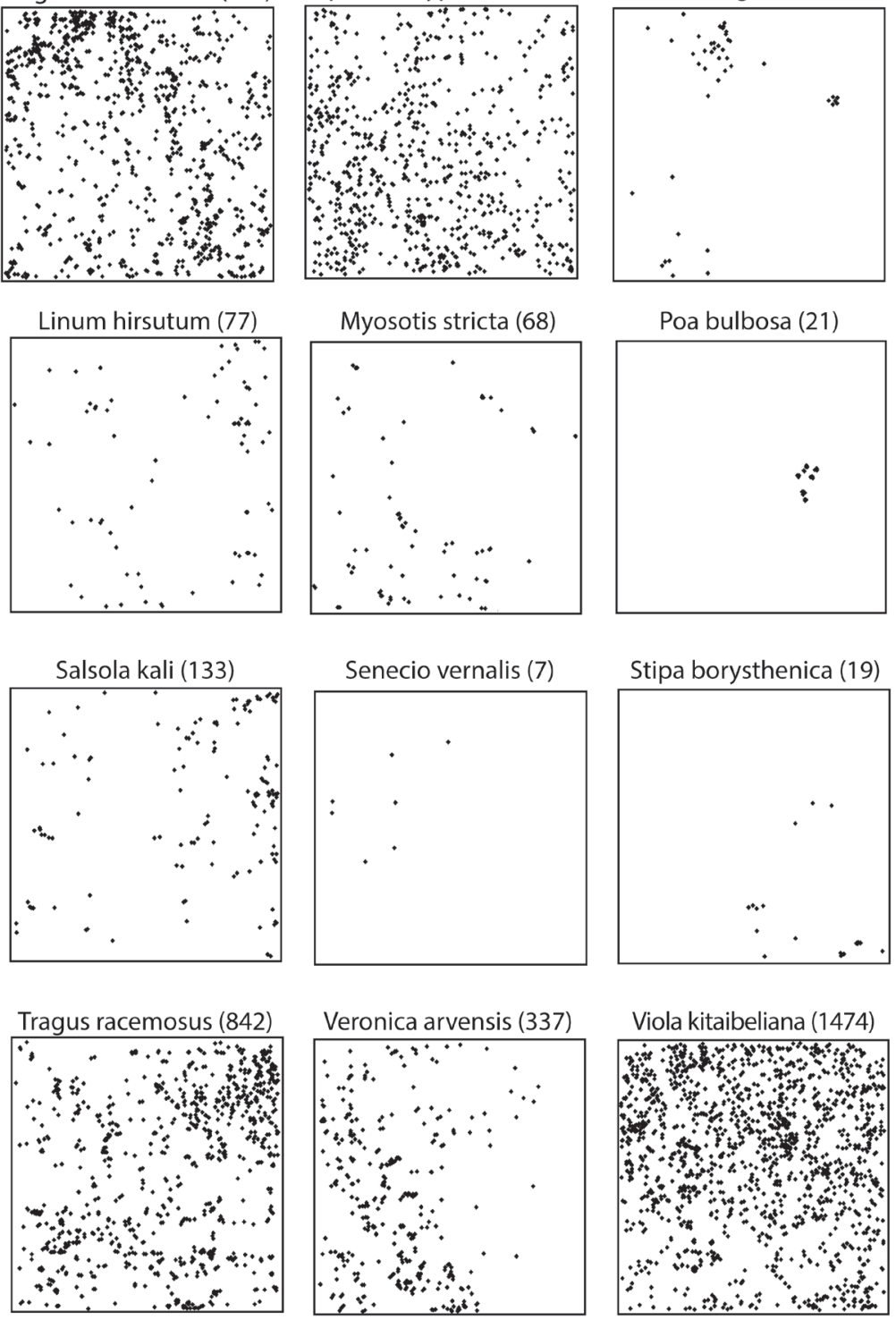

Figure 1. Spatial pattern of the 18 species sampled within a $4 \mathrm{~m} \times 4 \mathrm{~m}$ tract of a sand-steppe community near Bugac (Hungary). The numbers in brackets are the total number of individuals of each species. 
ramets within an area of $4 \mathrm{~m} \times 4 \mathrm{~m}$ were recorded by Podani et al. (1998). Total number of species is 18 ; total number of individuals is 5086 (Fig. 1). For procedures to create such point maps in the field, see Rohlf and Archie (1978). While the size of the study area is relatively small, in terms of sampling effort the number of individuals used in this paper is comparable with that of more classical studies on densitydependent processes in tropical forests (see e.g., Paine et al. 2012, Uriarte et al. 2010).

\section{Construction of phylogenetic distances}

We constructed a matrix of phylogenetic distances for the species of the study site by analyzing coding DNA sequences of ribulose-1,5-bisphosphate carboxylase/oxygenase large subunit ( $r b c L$ ) genes of the listed species, or closest relatives when no sequence was available for a particular taxon. The species and the NCBI GenBank accession numbers (in brackets) are as follows: Alkanna tinctoria (EU599849), Myosotis stricta (HM850191), Veronica arvensis (HM850447), Crepis rubra (AB530961), Conyza scabrida (AM234861), Senecio mikanioides (L13933), Arenaria drummondii (M83541), Salsola kali (HM850332), Euphorbia polychroma (AY794827), Linum hirsutum (FJ169583), Viola palustris (HM850468), Bromus sterilis (AY836155), Stipa dregeana (U31442), Calamagrostis epigeios (AJ784820), Koeleria pyramidata (AJ784825), Poa trivialis (HM850270), Tragus racemosus (EF125103), Colchicum speciosum (L12673). The distance matrix was calculated with the 2-parameter nucleotide substitution model of Kimura (1980) by the Dnadist program of the PHYLIP package (Felsenstein 2005).

\section{Null model}

The proposed phylogenetic individual-centered analysis was performed by increasing the circle radius from 5 to $60 \mathrm{~cm}$ in successive increments of $5 \mathrm{~cm}$ and calculating the mean phylogenetic distance between the focal individual and all neighbors within the circular ring (hereafter simply circle) delimited by two successive radii. The deviation from random expectation of MPD for the five most abundant species and for the entire community is computed using permutation methods. The selection of an adequate null model to test for community assembly rules is a critical operation as slightly different randomization procedures may imply considerably different null hypotheses. Therefore, when selecting a randomization algorithm, it is essential to break down only the structure in the original data set related to the null hypothesis to be tested, keeping every other feature unchanged (Gotelli and Graves 1996, Hardy 2008). A common null model for testing for non-random community structure is complete spatial randomness in the species spatial distribution (Podani and Czárán 1997). However, in plant assemblages limited dispersal induces spatial autocorrelation in species densities, giving rise to conspecific clustering. This concentration of conspecifics within clusters may lead to inflated type I errors if (phylogenetic) community structure is tested against a completely random pattern. A variety of methods have been proposed for constructing null models of spatially-explicit multispecies assemblages, which control for the autocorrelation patterns of species (discussed in Fuller and Enquist 2012). In marked point pattern analysis, a common approach consists in producing null models by generating simulated point patterns for each species with statistical properties similar to the observed distribution (Illian et al. 2008). In this paper, we used instead the following restricted randomization procedure: given an empirical distance threshold $\mathrm{D}$, the positions of two randomly selected individuals $i$ and $j$ are swapped if their spatial distance $d_{i j}$ is below the selected threshold ( $D$ > $\mathrm{d}_{\mathrm{ij}}$ ). If the distance between both individuals is larger than $\mathrm{D}$, the shuffle is aborted and a new pair of individuals is selected. This operation is repeated unless all possible pairs of individuals are swapped, with the additional constraint that each individual is swapped no more than once. For small values of $\mathrm{D}$, this constrained pairwise shuffling procedure disrupts the species phylogenetic structure only locally, while preserving the coarse-scale spatial distribution of species (Wiegand et al. 2007). For higher values of $D$, the species phylogenetic structure is disrupted at increasingly larger scales.

In this study, three distance thresholds of 15,30 and 60 $\mathrm{cm}$ were used for randomization. For each combination of radius $\mathrm{R}$ and threshold distance $\mathrm{D}, 999$ randomizations were performed. P-values were then computed as the proportion of permutation-derived values of MPD that are as extreme as or more extreme than the observed values. All analyses were run with the program TreeCreeper (Heathfield et al. 2012), freely available for download together with the user's manual at http://www.ecoap.unina.it/doc/publications.htm.

To avoid severe edge effects resulting from increasing circle radius, we restricted the analysis to individuals located in a central portion of $2.8 \mathrm{~m} \times 2.8 \mathrm{~m}$ of the study area (i.e., roughly $50 \%$ of total area), letting a buffer zone $60 \mathrm{~cm}$ wide all around. Thus, only the circles placed around the individuals comprised within this central quadrat were used for analysis, but all individuals in the study area were counted if they fell within a circle, regardless of whether they were inside or outside the central quadrat. The size of this quadrat was empirically selected in order to get a reasonable compromise between two opposing requirements: a large number of individuals within the quadrat to provide sufficiently accurate results versus an ample buffer zone that minimizes edge effects. An alternative correction for edge effects would consist in placing a circle around each individual in the study area and then weighting the MPD values associated to each circle by the proportion of the circle that falls within the study area (Rosenberg and Anderson 2011).

To compare our results with spatial distributions of known characteristics, we generated three artificial communities with varying patterns of Viola kitaibeliana (i.e., the most abundant species in the plot), while keeping the location of all remaining species unchanged with respect to Figure 1:

1. Regular pattern. 1521 (i.e., $39 \times 39$ ) individuals of Viola kitaibeliana, are regularly spaced within the study area (thus simulating maximal spatial segregation among individuals). 
2. Clumped pattern. The 1474 individuals of Viola kitaibeliana form small clusters, which are randomly distributed within the plot.

3. Random pattern. The 1474 individuals of Viola kitaibeliana are randomly distributed across the study area.

\section{Results}

The observed MPD values vs. increasing radii of the plots placed around the individuals of the five most abundant species (Erigeron canadensis, Euphorbia cyparissias, Tragus racemosus, Veronica arvensis and Viola kitaibeliana) and for the entire community are shown in Figure 2, together with the random expectations for $\mathrm{D}=15,30$, and $60 \mathrm{~cm}$. For $\mathrm{R}$ $=5 \mathrm{~cm}$, the MPDs of all species in Figure 2 are significantly lower than expected ( $\mathrm{P}<0.05$; two-tailed test $)$ and tend to increase very rapidly with increasing radius. This marked phylogenetic clustering in the immediate neighborhood of the sample individuals denotes that plants tend to occur in small conspecific clumps, while the individuals located at increasingly larger distances tend to be more phylogenetically distinct. For $\mathrm{R}>5 \mathrm{~cm}$, the species phylogenetic aggregation becomes progressively less intense and the curves of MPD vs. $\mathrm{R}$ show a flatter pattern composed of species-specific 'peaks' (local maxima) and 'saddles' (local minima) resulting from the alternation of patches and gaps in the species spatial distribution. The same pattern is also observed at the community level. However, this community-level pattern is obtained as the result of the complex spatial interaction of many species, each with its own local maxima and minima. Therefore, at the community level, the plot of mean phylogenetic distance vs. circle radii shows a smoother behavior than for single species with less pronounced peaks and saddles.

The profiles of MPD vs. R for Viola kitaibeliana and for the entire community calculated using the artificial patterns of this species are shown in Figure 3, together with the corresponding random expectations for $\mathrm{D}=30 \mathrm{~cm}$. The random expectations for $\mathrm{D}=15$ and $60 \mathrm{~cm}$ are qualitatively similar to the profiles in Figure 3, so we report only results for $\mathrm{D}=30$ $\mathrm{cm}$. Like in Figure 2, the community-level profiles of MPD vs. R show a smoother behavior compared to the corresponding profiles of Viola kitaibeliana. This is because communitylevel profiles reflect the phylogenetic structure of all individuals in the study area, and not only of the dominant species.

The species-level and community-level profiles of MPD vs. R obtained from the regular pattern of Viola kitaibeliana (corresponding to maximal spatial segregation among the individuals of this species) show strong oscillations between local maxima and minima. On the other hand, the profiles obtained from the random distribution of Viola do not show any significant departure of MPD from null expectation. Finally, the profiles obtained from the artificial clumped pattern in Figure 3 are very similar to the actual profiles in Figure 2. Accordingly, the observed plots of MPD vs. R in Figure 2 may be considered distinctive of a spatial organization in which the individual plants grow in small conspecific clumps showing short-range phylogenetic clustering, while at larger distances the observed phylogenetic clustering is progressively substituted by a random arrangement of such patches (and not only of individual plants) across the study area.

\section{Discussion}

The increasing availability of spatially-explicit ecological datasets has triggered growing interest in marked point pattern research (Wiegand et al. 2007, Law et al. 2009, Rajala and Illian 2012). The proposed measure of phylogenetic community structure can be used to detect characteristic distances at which the MPD within circular rings centered on a sample individual shows departure from null expectation. In the particular case of our study, for $\mathrm{R} \leq 10 \mathrm{~cm}$, strong effects of phylogenetic aggregation prevail, reflecting the presence of small conspecific clumps that are likely the result of distance-limited seed dispersal. In principle, for clonal or multistemmed plants, like Euphorbia cyparissias (Klimešová and de Bello 2009), these clumps may be composed of ramets of the same individual rather than being originated by dispersal mechanisms. However, fine-scale phylogenetic aggregation is also present for non-clonal species, such as Erigeron canadensis (Stanisci et al. 2010, Thuiller et al. 2012), thus showing that the observed pattern is not a mere effect of pseudo-replication.

For $\mathrm{R} \geq 10 \mathrm{~cm}$, the observed short-range spatial aggregation induced by limited dispersal is progressively disrupted. Since our analysis is based on static spatial data, we cannot determine which process(es) contribute to disrupting phylogenetic clustering at coarser scales (e.g., density-dependent mortality, intraspecific competition, or patchy habitat distribution). Nonetheless, in recent years, negative plant-soil feedback, that is, 'changes to soil properties that are caused by plants, which in turn influence the performance of plants' (van der Putten et al. 2013), is increasingly recognized as an important factor affecting natural plant communities and allowing species coexistence (Bever et al. 1997, Bonanomi et al. 2005).

Negative plant-soil feedback has been observed in a variety of environments, including grasslands (Klironomos 2002, Reynolds et al. 2003, Petermann et al. 2008), temperate and tropical forests (Packer and Clay 2000, Mangan et al. 2010, Comita et al. 2010, Johnson et al. 2012, Terborgh 2012) or anthropogenic landscapes (Singh et al. 1999) and the large body of observed patterns on species-specific negative plantsoil feedbacks has been related to different non-mutually exclusive mechanisms (reviewed in van der Putten et al. 2013). In this framework, Mazzoleni et al. (2015a) investigated the autotoxic effect of decomposed litter of twenty plant species from Mediterranean and temperate environments on root proliferation in different bioassays. Their results indicate a general occurrence of litter autotoxicity related to the exposure to fragmented extracellular DNA. Hence, while the effects of negative plant-soil feedback on the spatial structure of individual plants depend on the intensity of the underlying density-dependent mechanisms (Bagchi et al. 2010), its ubiquitous presence suggests that plant-soil feedback may play an important role in the maintenance of plant diversity in natural 

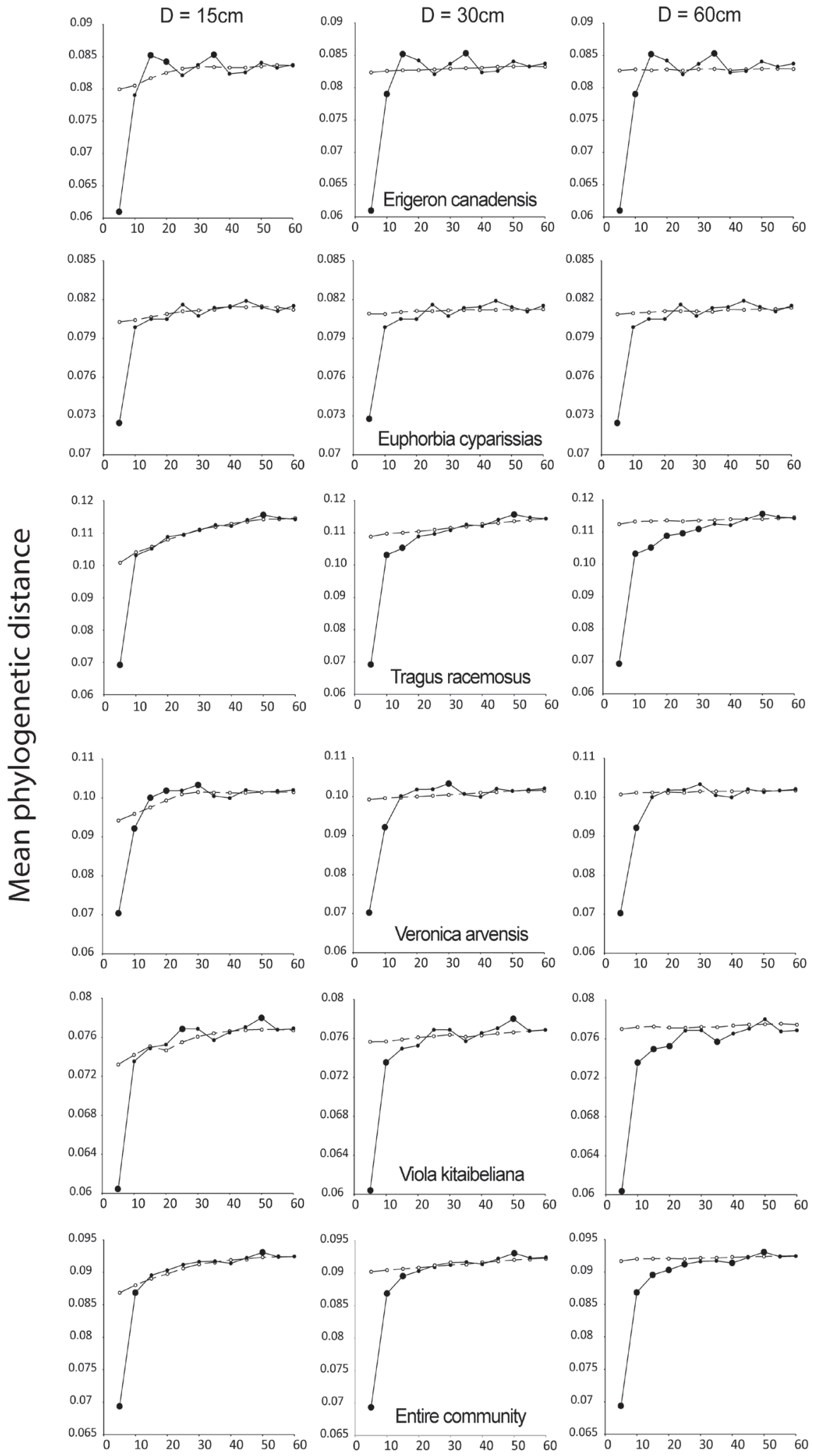

\section{Circle radius $(\mathrm{cm})$}

Figure 2. Observed mean phylogenetic distance MPD vs. circle radius R for the circular plots placed around the individuals of the five most abundant species in the study area (filled circles and continuous lines), together with the random expectations for randomization distances $\mathrm{D}=15,30$, and $60 \mathrm{~cm}$ (open circles and dotted lines). Filled circles falling below the dotted line show phylogenetic clustering; filled circles falling above the dotted line show phylogenetic segregation. Large circles represent phylogenetic distances that are significantly different from random expectation (two-tailed test; $\mathrm{p}=0.05 ; 999$ randomizations). 

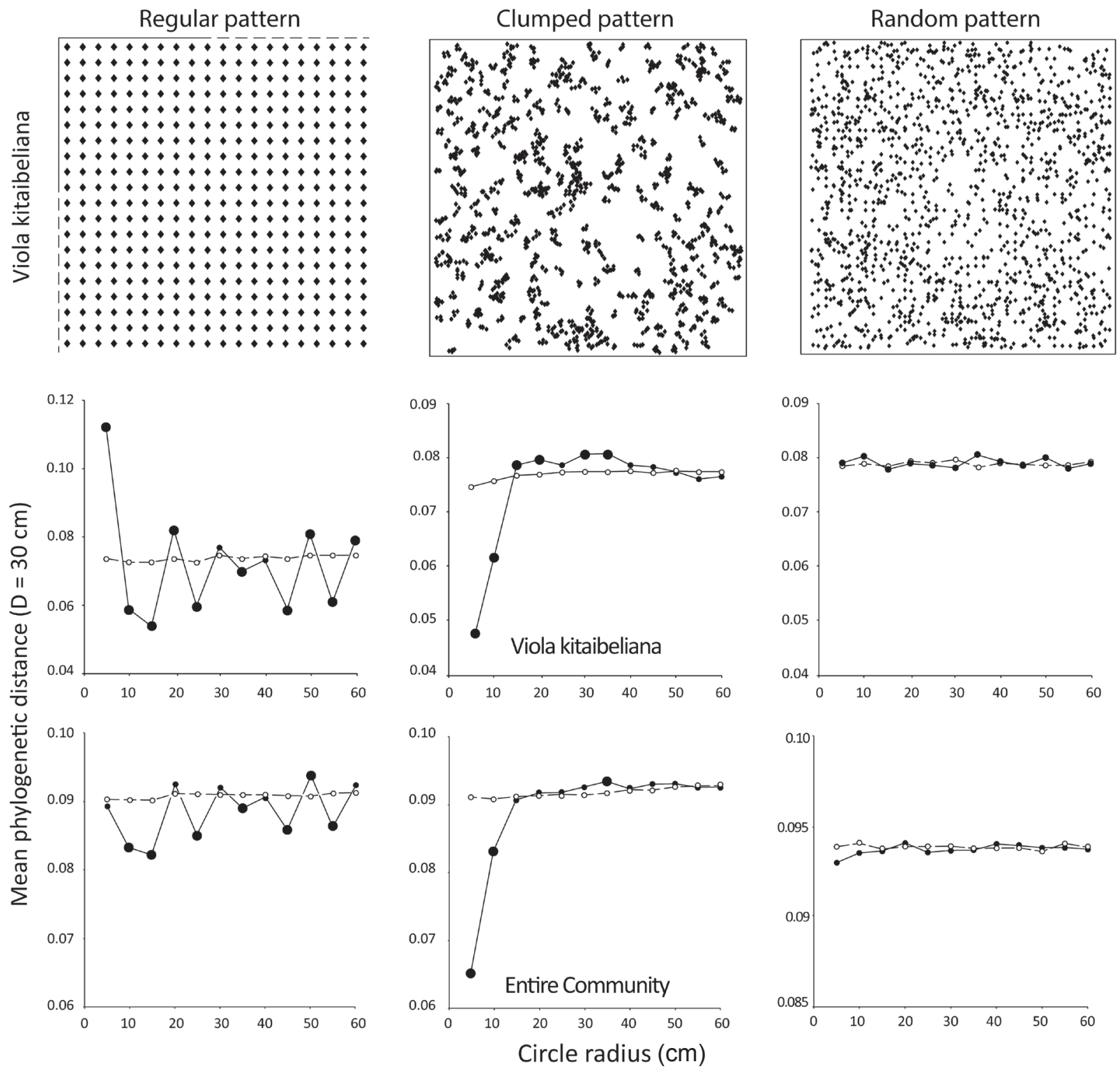

Figure 3. Observed mean phylogenetic distance MPD vs. circle radius R (filled circles and continuous line) for Viola kitaibeliana and for the entire community calculated using the artificial patterns of Viola referred to in the text as 'regular', 'clumped', and 'random'. The spatial structure of all remaining species is unchanged with respect to Figure 1. The open circles and the dotted line show the random expectations for $\mathrm{D}=30 \mathrm{~cm}$. Large circles represent phylogenetic distances that are significantly different from random expectation (two-tailed test; $\mathrm{p}=0.05 ; 999$ randomizations).

communities (Mazzoleni et al. 2015b). In a review on direct evidences on conspecific negative plant-soil feedback from both terrestrial and aquatic plants, Mazzoleni et al. (2007) reported 138 cases of conspecific negative plant-substrate interactions, 96 of which are associated with grassland species, including Erigeron canadensis, one species of Veronica and one species of Viola, thus reinforcing the hypothesis that plant-soil feedbacks may contribute to the disruption of shortrange phylogenetic clustering (see also Anacker et al. 2014).

From a statistical viewpoint, whether the observed values of MPD are extreme enough to be considered significantly different from random expectation varies with randomization distance. For short randomization distances, we mainly dis- rupt the local conspecific clusters while preserving to some extent the coarser-scale species spatial organization, whereas by increasing $\mathrm{D}$ we disrupt the species spatial organization at increasingly larger distances. As a result, the curves of random expectation in Figure 2 are gradually shifted towards higher values of MPD, particularly for small values of $\mathrm{R}$. This raises the question of how to select a biologically meaningful species-specific randomization distance. Here, a promising approach may consist in selecting species-specific randomization distances that reflect the degree of spatial aggregation of each species (see e.g., Seidler and Plotkin 2006). As the testing method uses a statistic with dependent values at different ranges, inflated type I errors may occur (Grabarnik 
et al. 2011). Accordingly, to adjust the testing for multiple scales, thus avoiding the problem of simultaneous inference, a deviation test (Grabarnik et al. 2011) may be adopted. Also, besides classical p-value testing, alternative approaches such as model validation techniques (Ling and Mahadevan 2013) may also be considered.

An additional limitation of the proposed procedure is that the individual plants are treated as dimensionless points in space without considering their actual spatial extension. However, plant dimensions can be incorporated either by grouping individuals of different size into separate classes, or through a weighting procedure such that large individuals may have a greater weight in the computation of MPD than small ones (Podani and Czárán 1997). Although the present version of our program does not include such weighting option, the source code can be freely downloaded from the Codeplex open source software repository web site: http:// treecreeper.codeplex.com/ to be modified according to the users' requirements.

Finally note that the proposed multispecies generalization of point pattern analysis necessarily requires assigning a distance measure to each pair of species. As the species are not all equally distinct in evolutionary terms, using phylogenetic distances represents a biologically meaningful way for characterizing species pairs and for analyzing the spatial pattern of the entire community. Nonetheless, the same individualcentered analysis may be easily performed based on any other distance measure, such as functional distance, which is believed to reflect ecological differences between species in an ecologically meaningful way.

\section{References}

Anacker, B.L., Klironomos, J.N., Maherali, H., Reinhart, K.O. and Strauss S.Y. 2014. Phylogenetic conservatism in plant-soil feedback and its implications for plant abundance. Ecol. Lett. 17: 1613-1621.

Bagchi, R., Swinfield, S., Gallery, R.E., Lewis, O.T., Gripenberg, S., Narayan, L. and Freckleton R.P. 2010. Testing the JanzenConnell mechanism: pathogens cause overcompensating density dependence in a tropical tree. Ecol. Lett. 13: 1262-1269.

Bever, J.D. 1994. Feedback between plants and their soil communities in an old field community. Ecology 75: 1965-1977.

Bever, J.D., Westover, M. and Antonovics, J. 1997. Incorporating the soil community into plant population dynamics: the utility of the feedback approach. J. Ecol. 85: 561-573.

Bonanomi, G., Antignani, V., Capodilupo, M. and Scala, F. 2010. Identifying the characteristics of organic soil amendments that suppress soilborne plant diseases. Soil Biol. Biochem. 42: 136144.

Bonanomi, G., Giannino, F. and Mazzoleni, S. 2005. Negative plantsoil feedback and species coexistence. Oikos 111: 311-321.

Cadotte, M.W., Davies, T.J., Regetz, J., Kembel, S.W., Cleland, E. and Oakley, T.H. 2010. Phylogenetic diversity metrics for ecological communities: integrating species richness, abundance and evolutionary history. Ecol. Lett. 13: 96-105.

Cavender-Bares, J., Kozak, K.H., Fine, P.V.A. and Kembel, S.W. 2009. The merging of community ecology and phylogenetic biology. Ecol. Lett. 12: 693-715.
Chave, J., Muller-Landau, H.C. and Levin, S.A. 2002. Comparing classical community models: Theoretical consequences for patterns of diversity. Amer. Nat. 159: 1-23.

Chesson, P. 2000. Mechanisms of maintenance of species diversity. Annu. Rev. Ecol. Evol. Syst. 31: 343-366.

Coley, P.D. and Barone, J.A. 1996. Herbivory and plant defenses in tropical forests. Annu. Rev. Ecol. Evol. Syst. 27: 305-335.

Comita, L.S., Muller-Landau, H.C., Aguilar, S. and Hubbell S.P. 2010. Asymmetric density dependence shapes species abundances in a tropical tree community. Science 329: 330-332.

Connell, J.H. 1971. On the role of natural enemies in preventing competitive exclusion in some marine animals and in rain forest trees. In: den Boer, P.J. and Gradwell, G.R. (eds.), Dynamics of Populations. Center for Agricultural Publishing and Documentation, Wageningen, NL. pp. 298-312.

Devictor, V., Mouillot, D., Meynard, C., Jiguet, F., Thuiller, W. and Mouquet, N. 2010. Spatial mismatch and congruence between taxonomic, phylogenetic and functional diversity: the need for integrative conservation strategies in a changing world. Ecol. Lett. 13: 1030-1040.

Diggle, P.J. 2003. Statistical Analysis of Spatial Point Patterns. Arnold, London.

Felsenstein, J. 2005. PHYLIP (Phylogeny Inference Package) version 3.6. Department of Genetics, University of Washington, Seattle.

Ferrier, S., Manion, G., Elith, J. and Richardson K. 2007. Using generalized dissimilarity modelling to analyse and predict patterns of beta diversity in regional biodiversity assessment. Divers. Distrib. 13: 252-264.

Fuller, M.M. and Enquist, B.J. 2012. Accounting for spatial autocorrelation in null models of tree species association. Ecography 35: $510-518$

Gilbert, G.S. and Webb, C.O. 2007. Phylogenetic signal in plant pathogen-host range. PNAS USA 104: 4979-4983.

Gonzalez, M.A., Roger, A., Courtois, E.A., Jabot, F., Norden, N., Paine, C.E.T., Baraloto, C., Thébaud, C. and Chave, J. 2010. Shifts in species and phylogenetic diversity between sapling and tree communities indicate negative density dependence in a lowland rain forest. J. Ecol. 98: 137-146.

Gotelli, N.J. and Graves, G.R. 1996. Null Models in Ecology. Smithsonian Institution Press, Washington.

Grabarnik, P., Myllymaki, M. and Stoyan, D. 2011. Correct testing of mark independence for marked point patterns. Ecol. Model. 222: 3888-3894.

Hardy, O.J. 2008. Testing the spatial phylogenetic structure of local communities: statistical performances of different null models and test statistics on a locally neutral community. J. Ecol. 96: 914-926.

Heathfield, D., Kivistö, V., Mazzoleni, S. and Ricotta C. 2012. TreeCreeper a Computer Program for the Taxonomic Analysis of Species Assemblages. Department of Forestry and Environmental Sciences, University of Naples 'Federico II', Portici, Italy and World in a Box, Karkkila, Finland.

Illian, J., Penttinen, A., Stoyan, H. and Stoyan, D. 2008. Statistical Analysis and Modelling of Spatial Point Patterns. Wiley, Chichester.

Janzen, D.H. 1970. Herbivores and the numbers of tree species in tropical forests. Amer. Nat. 104: 501-528.

Johnson, D.J., Beaulieu, W.T., Bever, J.D. and Clay, K. 2012. Conspecific negative density dependence and forest diversity. Science 336: 904-907. 
Kimura, M. 1980. A simple method for estimating evolutionary rates of base substitutions through comparative studies of nucleotide sequences. J. Mol. Evol. 16: 111-120.

Klimešová, J. and de Bello F. 2009. CLO-PLA: the database of clonal and bud bank traits of Central European flora. J. Veg. Sci. 20: 511-516.

Klironomos, J.N. 2002. Feedback with soil biota contributes to plant rarity and invasiveness in communities. Nature 417: 67-70.

Kraft, N.J.B. and Ackerly, D.D. 2010. Functional trait and phylogenetic tests of community assembly across spatial scales in an Amazonian forest. Ecol. Monog. 80: 401-422.

Law, R., Illian, J., Burslem, D.F.R.P., Gratzer, G., Gunatilleke, C.V.S and Gunatilleke, I.A.U.N. 2009. Ecological information from spatial patterns of plants: insights from point process theory. $J$. Ecol. 97: 616-628

Ling, Y. and Mahadevan, S. 2013. Quantitative model validation techniques: New insights. Reliability Engineering and System Safety 111: 217-231.

Losos, J.B. 2008. Phylogenetic niche conservatism, phylogenetic signal and the relationship between phylogenetic relatedness and ecological similarity among species. Ecol. Lett. 11: 995-1007.

Mangan, S.A., Schnitzer, S.A., Herre, E.A., Mack, K.M.L., Valencia, M.C., Sanchez, E.I. and Bever J.D. 2010. Negative plant-soil feedback predicts tree-species relative abundance in a tropical forest. Nature 466: 752-755.

Mazzoleni, S., Bonanomi, G., Giannino, F., Rietkerk, M., Dekker, S. and Zucconi, F. 2007. Is plant biodiversity driven by decomposition processes? An emerging new theory on plant diversity. Community Ecol. 8: 103-109.

Mazzoleni, S., Bonanomi, G., Incerti, G., Chiusano, M.L., Termolino, P., Mingo, A., Senatore, M., Giannino, F., Cartenì, F., Rietkerk M. and Lanzotti, V. 2015a. Inhibitory and toxic effects of extracellular self-DNA in litter: a mechanism for negative plant-soil feedbacks? New Phytol. 205: 1195-1210.

Mazzoleni, S., Cartenì, F., Bonanomi, G., Senatore, M., Termolino, P., Giannino, F., Incerti, G., Rietkerk, M., Lanzotti, V. and Chiusano, M.L. 2015b. Inhibitory effects of extracellular selfDNA: a general biological process? New Phytol. 206: 127-132.

Metz, M.R., Sousa, W.P. and Valencia, R. 2010. Widespread densitydependent seedling mortality promotes species coexistence in a highly diverse Amazonian rain forest. Ecology 91: 3675-3685.

Milla, R., Escudero, A. and Iriondo, J.M. 2009. Inherited variability in multiple traits determines fitness in populations of an annual legume from contrasting latitudinal origins. Ann. Bot. 103: 1279-1289.

Morlon, H., Schwilk, D.W., Bryant, J.A., Marquet, P.A., Rebelo, A.G., Tauss, C., Bohannan, B.J.M. and Green, J.L. 2010. Spatial patterns of phylogenetic diversity. Ecol. Lett. 14: 141-149.

Ness, J.H., Rollinson, E.J. and Whitney, K.D. 2011. Phylogenetic distance can predict susceptibility to attack by natural enemies. Oikos 120: 1327-1334.

Novotny, V., Miller, S.E., Baje, L., Balagawi, S., Basset, Y., Cizek, L., Craft, K.J., Dem, F., Drew, R.A.I., Hulcr, J., Leps, J., Lewis, O.T., Pokon, R., Stewart, A.J.A., Samuelson, G.A. and Weiblen, G.D. 2010. Guild-specific patterns of species richness and host specialization in plant-herbivore food webs from a tropical forest. J. Anim. Ecol. 79: 1193-1203.

Packer A., Clay K. (2000) Soil pathogens and spatial patterns of seedling mortality in a temperate tree. Nature 404: 278-281.

Paine, C.E.T., Norden, N., Chave, J., Forget, P.M., Fortunel, C., Dexter, K.G. and Baraloto, C. 2012. Phylogenetic density de- pendence and environmental filtering predict seedling mortality in a tropical forest. Ecol. Lett. 15: 34-41.

Petermann, J.S., Fergus, A.J.F., Turnbull, A. and Schmid, B. 2008. Janzen-Connell effects are widespread and strong enough to maintain diversity in grasslands. Ecology 89: 2399-2406.

Podani, J. and Czárán, T. 1997. Individual-centered analysis of mapped point patterns representing multi-species assemblages. J. Veg. Sci. 8: 259-270.

Podani, J., Czárán, T. and Scheuring, I. 1998. Individual-centered analysis of community pattern: some case studies. Abstr. Bot. 22: $101-112$

Rajala, T. and Illian, J. 2012. A family of spatial biodiversity measures based on graphs. Environ. Ecol. Stat. 19: 545-572.

Reynolds, H.L., Packer, A., Bever, J.D. and Clay, K. 2003. Grassroots ecology: plant-microbe-soil interactions as drivers of plant community structure and dynamics. Ecology 84: 2281-2291.

Ripley, BD 1981. Spatial Statistics. Wiley, New York.

Rohlf, F.J. and Archie, J.W. 1978. Least-squares mapping using interpoint distances. Ecology 59: 126-132.

Rosenberg, M.S. and Anderson, C.D. 2011. PASSaGE: Pattern Analysis, Spatial Statistics and Geographic Exegesis. Version 2. Meth. Ecol. Evol. 2: 229-232.

Seidler, T.G. and Plotkin, J.B. 2006. Seed dispersal and spatial pattern in tropical trees. PLoS Biol. 4: e344. DOI: 10.1371/journal. pbio.0040344.

Simon, T. 1992. Guide to the Vascular Flora of Hungary. Tankönyvkiadó, Budapest (in Hungarian).

Singh, H.P., Batish, R.D. and Kohli, K.R. 1999. Autotoxicity: concept, organisms and ecological significance. Crit. Rev. Plant Sci. 18: $757-772$

Stanisci, A., Acosta, A.T.R., Di Iorio, A. and Vergalito, M. 2010 Leaf and root trait variability of alien and native species along Adriatic coastal dunes (Italy). Plant Biosyst. 144: 47-52.

Terborgh, J. 2012. Enemies maintain hyperdiverse tropical forests. Amer. Nat. 179: 303-314.

Thompson, K., Petchey, O.L., Askew, A.P., Dunnett, N.P., Beckerman, A.P. and Willis, A.J. 2010. Little evidence for limiting similarity in a long-term study of a roadside plant community. J. Ecol. 98: 480-487.

Thuiller, W., Gasso, N., Pino, J. and Vilà, M. 2012. Ecological niche and species traits: key drivers of regional plant invader assemblages. Biol. Invasions 14: 1963-1980.

Uriarte, M., Swenson, N.G., Chazdon, R.L., Comita, L.S., Kress, W.J., Erickson, D., Forero-Montana, J., Zimmerman, J.K. and Thompson, J. 2010. Trait similarity, shared ancestry and the structure of neighbourhood interactions in a subtropical wet forest: implications for community assembly. Ecol. Lett. 13: 1503-1514.

Vamosi, S.M., Heard, S.B., Vamosi, J.C. and Webb C.O. 2009. Emerging patterns in the comparative analysis of phylogenetic community structure. Mol. Ecol. 18: 572-592.

Van der Putten, W.H., Bardgett, R.D., Bever, J.D., Bezemer, T.M., Casper, B.B., Fukami, T., Kardol, P., Klironomos, J.N., Kulmatiski, A., Schweitzer, J.A., Suding, K.N., Van de Voorde, T.F.J. and Wardle, D.A. 2013. Plant-soil feedbacks: the past, the present and future challenges. J. Ecol. 101: 265-276.

Van der Putten, W.H., Van Dijk, C. and Peters, B.A.M. 1993. Plantspecific soil-borne diseases contribute to succession in foredune vegetation. Nature 362: 53-56. 
Webb, C.O., Ackerly, D.D., McPeek, M.A. and Donoghue, M.J. 2002. Phylogenies and community ecology. Annu. Rev. Ecol. Evol. Syst. 33: 475-505.

Webb, C.O., Gilbert, G.S. and Donoghue, M.J. 2006. Phylodiversitydependent seedling mortality, size structure, and disease in a Bornean rain forest. Ecology 87: S123-S131.
Wiegand, T., Gunatilleke, C.V.S., Gunatilleke, I.A.U.N. and Huth, A. 2007. How individual species structure diversity in tropical forests. PNAS USA 104: 19029-19033.

Received March 14, 2017

Revised April 28, 2017

Accepted May 2, 2017 